\title{
What We Talk about When We Talk about Caregiving: The Distribution of Roles in Cancer Patient Caregiving in a Family-Oriented Culture
}

\author{
Ansuk Jeong, $\mathrm{PhD}{ }^{1}$ \\ Dongwook Shin, MD, MBA, DrPH² \\ Jong Hyock Park, MD, MPH, PhD ${ }^{3}$ \\ Keeho Park, MD, PhD ${ }^{4}$
}

${ }^{1}$ Department of Psychology, The University of Utah Asia Campus, Incheon, ${ }^{2}$ Department of Family Medicine/Supportive Care Center, Samsung Medical Center, Sungkyunkwan University College of Medicine, Seoul, ${ }^{3}$ College of Medicine/Graduate School of Health Science Business Convergence, Chungbuk National University, Cheongju, ${ }^{4}$ Cancer Policy Branch, National Cancer Center, Goyang, Korea
Correspondence: Dongwook Shin, MD, MBA, DrPH Department of Family Medicine/Supportive Care Center, Samsung Medical Center, Sungkyunkwan University College of Medicine, 81 Irwon-ro, Seoul 06351, Korea

Tel: 82-2-6190-5252

Fax: 82-2-3410-5252

E-mail: dwshin.md@gmail.com

Co-correspondence: Keeho Park, MD, PhD

Cancer Policy Branch, National Cancer Center, 323 Ilsan-ro, Goyang 10408, Korea

Tel: $82-31-920-2160$

Fax: 82-31-920-2949

E-mail: park.keeho@gmail.com

\section{Key words}

Cancer care, Caregivers, Role, Republic of Korea, Culture, Psycho-oncology 


\section{Introduction}

Cancer caregiving involves multiple tasks. The list of tasks can include, but not limited to, accompanying the patient to doctor's appointments; communicating with the medical professionals so that the patient can make best decisions [1]; being physically available for the patient in order to help out his / her daily functioning; providing emotional support; and financial arrangement when the needs arise [1-3].

These multiple tasks oftentimes involve multiple caregivers. As the current literature generally takes one caregiver as the primary one, however, not much is known about the distribution of the roles among multiple family members. Even though there is a body of literature that investigated different expectations and attitudes toward caregiving and different manifestation of familism in different cultures [4-9], the specific roles and the distribution of the roles among multiple family members did not get much attention. Considering the family-oriented Korean culture as an important context of caregiving, therefore, it is worth investigating the distribution of responsibilities in cancer caregiving within family.

What is also unknown is whether the source of support is different depending on family structure, gender, and age of the patients. From the perspective of sharing the caregiving responsibility, it is worth investigating whether different family types with different persons available to provide care present different patterns of responsibility distribution. Considering the different gender roles across diverse cultures, it is worth examining who takes what caring role in the family, whether it is consistent with the gender expectation. Furthermore, as the patient ages, the functional and mental status of the patient might facilitate their dependence on family caregivers. Thus, it is worthwhile to test the effect of age as well.

In this regard, the current study aims first to describe the roles of family caregivers with respect to the support they provide for the cancer patient family member, and second to relate them to the patient's family structure, gender, and age. More specifically the current study will contextualize the distribution of responsibilities to provide care for the elderly cancer patients in the Korean cultural context, where each family takes care of diverse aspects of individual's wellbeing.

\section{Materials and Methods}

\section{Participants}

National Cancer Center of Korea has been conducting Cancer Patient Experience (CaPE) survey since 2008. In the year of 2014, the focus was put on the elderly cancer patients in order to examine the specific needs and experiences of people who had been diagnosed with cancer. Even though 65 and above are often agreed to be the "elderly," 60 or above were included in the current study as the elderly. In the Korean context, many industries set the retirement age at around 60, from which the cancer patient's reliance on the support of family members can become more conspicuous. The data was collected from National Cancer Center and 10 Regional Cancer Centers, which consists of a random sample from multiple regions. Only those cancer patients who were 60 or above were recruited in 2014. As the focus was the age factor, the types of cancer were limited to three, stomach, colorectal, and lung cancers, which rank the highest three cancers in this age group in Korea [10]. Anyone who volunteered to participate, as long as they have no psychological and linguistic barriers to complete the survey on their own, participated. A total of 439 elderly cancer patients completed the survey.

\section{Procedures}

The research participation opportunity was advertised through trained research assistants in the respective cancer departments in each of the participating cancer centers. Each participant completed the survey for him/herself. When the participants wanted aides in reading the survey items because of poor eyesight or in comprehending the questions regarding the sources of help, however, the research assistants helped read the questions or record the responses, as was in another study [11]. Also the participants' medical records were reviewed, under the participants' consents, to collect relevant data. The medical records retrieved include cancer stage, diagnosis date, treatment types and dates, and comorbidity.

\section{Measurements}

\section{1) Demographics}

Patient's demographical information included age, gender, living arrangement, marital status, education, income, religion, source of finance for the medical treatment, and types of insurance. To identify the family members who can function as available resources, participants were asked to 
respond whether they have a spouse, sons, daughters, sonsin-law, daughters-in-law, grandchildren, and siblings. This information on the availability, instead of the living arrangement, was used to identify the family structure in the current study as the geographical distance itself does not necessarily present a barrier for providing support in Korea.

\section{2) Caregiving roles}

In terms of the roles of caregiving, participants were asked to identify a respective family member who was in charge of physical support, emotional support [12,13], financial support, decision-making support [14,15], clinic visit support, and meal-prep support. The question items were created based on the literature on caregiving roles [1-3,12-15].

\section{Analysis}

For the analysis purpose, the participants were grouped into different family types: those with spouse, son(s), and daughter(s); those with son(s) and daughter(s); those with spouse and son(s); those with spouse and daughter(s); and those who are alone. Further, the participants' responses were compared between males and females and among different age groups. For the family type comparison, cross-tab method was used to describe the pattern of the distribution, instead of chi-square test due to the number of cells having expected count less than five [9]. Other comparisons, according to gender and age, were made using $\chi^{2}$ statistics.

\section{Ethical statement}

The survey was approved by the National Cancer Center's Institutional Review Board (NCCNCS13787).

\section{Results}

\section{Participant characteristics}

Table 1 shows the characteristics of the participants. On average, they were 70.8 years old, ranging from 60 to 90 . More than half (281 persons, $64 \%$ ) of the participants were male. About half of the participants $(48.8 \%)$ reported either no schooling or completing primary school. Two thirds of the participants (319 persons, $72.7 \%$ ) were married. More than three fifths $(64.7 \%)$ reported they are religious. $41.2 \%$ experienced gastric cancer, $39.4 \%$ colorectal cancer, and $19.4 \%$ lung cancer.
Table 1. Characteristics of participants $(n=439)$

\begin{tabular}{|lc|}
\hline Characteristic & No. $(\%)$ \\
\hline Age, mean \pm SD (yr) & $70.80 \pm 6.24$ \\
\hline Sex & \\
\hline Male & $281(64.0)$ \\
\hline Female & $158(36.0)$ \\
\hline Education & \\
\hline No schooling & $46(10.5)$ \\
\hline Elementary school & $168(38.3)$ \\
\hline Junior-high school & $82(18.7)$ \\
\hline High school & $101(23.0)$ \\
\hline College/University & $39(8.9)$ \\
\hline Post-graduate & $3(0.7)$ \\
\hline Marital status & \\
\hline Married & $319(72.7)$ \\
\hline Cohabitation & $13(3.0)$ \\
\hline Divorced/Separated & $22(5.0)$ \\
\hline Widowed & $83(18.9)$ \\
\hline Single & $2(0.5)$ \\
\hline Religion & \\
\hline No religion & $155(35.3)$ \\
\hline Protestant & $85(19.4)$ \\
\hline Catholic & $33(7.5)$ \\
\hline Buddhism & $160(36.4)$ \\
\hline Others & $6(1.4)$ \\
\hline Cancer type & $181(41.2)$ \\
\hline Colorectal cancer & $173(39.4)$ \\
\hline Lung cancer & $85(19.4)$ \\
\hline & $1.11 \pm 1.01$ \\
\hline Time since diagnosis, mean $\pm S D(y r)$ & \\
\hline
\end{tabular}

\section{Distribution of caregiving roles}

\section{1) By family type}

Out of the 439 participants (Table 1), 413 patients (94.1\%) belonged to the five family types: those with spouse, son(s), and daughter(s); those with son(s) and daughter(s); those with spouse and son(s); those with spouse and daughter(s); and those who are alone. And the rest were those with spouse only $(n=4)$, those with sons only $(n=13)$, and those with daughters only $(n=9)$. The following analyses were conducted with the major fvie family types.

Taking the availability of different resources of relationships in different family types into account, a consistent pattern was found (Table 2). First, spouse was the main source of physical $(71.2 \%)$, emotional $(68.6 \%)$, clinic visit $(49.1 \%)$, and meal prep $(64.6 \%)$ support. The reliance on spouse decreased when it comes to the financial (34.6\%) and decision-making $(41.7 \%)$ support, for which the roles of adult 
Table 2. Role distribution by family type

\begin{tabular}{|c|c|c|c|c|c|c|}
\hline & \multicolumn{5}{|c|}{ Family type } & \multirow[b]{2}{*}{ Total } \\
\hline & $\begin{array}{c}\text { Spouse+son } \\
\text { +daughter }\end{array}$ & $\begin{array}{c}\text { Son } \\
\text { +daughter }\end{array}$ & $\begin{array}{l}\text { Spouse } \\
+ \text { son }\end{array}$ & $\begin{array}{c}\text { Spouse } \\
\text { +daughter }\end{array}$ & Alone & \\
\hline No. & 227 & 81 & 64 & 35 & 3 & 410 \\
\hline \multicolumn{7}{|l|}{ Physical support } \\
\hline Self & $4(1.8)$ & $15(18.5)$ & $1(1.6)$ & $1(2.9)$ & $2(66.7)$ & $23(5.6)$ \\
\hline Spouse & $202(89.0)$ & NA & $61(95.3)$ & $29(82.9)$ & NA & $292(71.2)$ \\
\hline Son & $6(2.6)$ & $27(33.3)$ & $1(1.6)$ & NA & NA & $34(8.3)$ \\
\hline Daughter & $10(4.4)$ & $26(32.1)$ & NA & $5(14.3)$ & NA & $41(10.0)$ \\
\hline Daughter-in-law & $5(2.2)$ & $12(14.8)$ & $1(1.6)$ & NA & NA & $18(4.4)$ \\
\hline Others & 0 & $1(1.2)$ & 0 & 0 & $1(33.3)$ & $2(0.5)$ \\
\hline \multicolumn{7}{|l|}{ Emotional support } \\
\hline Self & $2(0.9)$ & $10(12.3)$ & $3(4.7)$ & 0 & $2(66.7)$ & $17(4.1)$ \\
\hline Spouse & $195(85.9)$ & NA & $59(92.2)$ & $27(77.1)$ & NA & $281(68.6)$ \\
\hline Son & $8(3.5)$ & $29(35.8)$ & $1(1.6)$ & NA & NA & $38(9.3)$ \\
\hline Daughter & $17(7.5)$ & $32(39.5)$ & NA & $8(22.9)$ & NA & $57(13.9)$ \\
\hline Daughter-in-law & $4(1.8)$ & $9(11.1)$ & $1(1.6)$ & NA & NA & $14(3.4)$ \\
\hline Others & $1(0.4)$ & $1(1.2)$ & 0 & 0 & $1(33.3)$ & $3(0.7)$ \\
\hline \multicolumn{7}{|l|}{ Financial support } \\
\hline Self & $41(18.1)$ & $21(25.9)$ & $23(35.9)$ & $8(22.9)$ & $2(66.7)$ & 95 (23.2) \\
\hline Spouse & $99(43.6)$ & NA & $19(29.7)$ & $24(68.6)$ & NA & $142(34.6)$ \\
\hline Son & $62(27.3)$ & $42(51.9)$ & $22(34.4)$ & NA & NA & $126(30.7)$ \\
\hline Daughter & $22(9.7)$ & $14(17.3)$ & NA & $3(8.6)$ & NA & $39(9.5)$ \\
\hline Daughter-in-law & $3(1.3)$ & $1(1.2)$ & 0 & NA & NA & $4(1.0)$ \\
\hline Son-in-law & 0 & $1(1.2)$ & NA & 0 & 0 & $1(0.2)$ \\
\hline Siblings & 0 & $1(1.2)$ & 0 & 0 & 0 & $1(0.2)$ \\
\hline Others & 0 & $1(1.2)$ & 0 & 0 & $1(33.3)$ & $2(0.5)$ \\
\hline \multicolumn{7}{|l|}{ Decision support } \\
\hline Self & $39(17.2)$ & $20(24.7)$ & $19(29.7)$ & $4(11.4)$ & $3(100)$ & $85(20.7)$ \\
\hline Spouse & $118(52.0)$ & NA & $29(45.3)$ & $24(68.6)$ & NA & $171(41.7)$ \\
\hline Son & 47 (20.7) & $40(49.4)$ & $14(21.9)$ & NA & NA & $101(24.6)$ \\
\hline Daughter & $19(8.4)$ & $17(21.0)$ & NA & $6(17.1)$ & NA & $42(10.2)$ \\
\hline Daughter-in-law & $4(1.8)$ & $3(3.7)$ & $1(1.6)$ & NA & NA & $8(2.0)$ \\
\hline Son-in-law & 0 & $1(1.2)$ & NA & 0 & 0 & $1(0.2)$ \\
\hline Siblings & 0 & 0 & $1(1.6)$ & $1(2.9)$ & 0 & $2(0.5)$ \\
\hline \multicolumn{7}{|l|}{ Clinic visit support } \\
\hline Self & $16(7.0)$ & $7(8.8)$ & $9(14.1)$ & $2(5.7)$ & $1(33.3)$ & $35(8.6)$ \\
\hline Spouse & $138(60.8)$ & NA & $39(60.9)$ & $24(68.6)$ & NA & $201(49.1)$ \\
\hline Son & $35(15.4)$ & $25(31.3)$ & $9(14.1)$ & NA & NA & $69(16.9)$ \\
\hline Daughter & $23(10.1)$ & $28(35.0)$ & NA & $9(25.7)$ & NA & $60(14.7)$ \\
\hline Daughter-in-law & $13(5.7)$ & $16(20.0)$ & $6(9.4)$ & NA & NA & $35(8.6)$ \\
\hline Son-in-law & $2(0.9)$ & $1(1.3)$ & NA & 0 & NA & $3(0.7)$ \\
\hline Siblings & 0 & 0 & $1(1.6)$ & 0 & $1(33.3)$ & $2(0.5)$ \\
\hline Others & 0 & $3(3.8)$ & 0 & 0 & $1(33.3)$ & $4(1.0)$ \\
\hline \multicolumn{7}{|l|}{ Meal prep support } \\
\hline Self & $36(15.9)$ & $52(64.2)$ & $7(10.9)$ & $7(20.0)$ & $3(100)$ & $105(25.6)$ \\
\hline Spouse & $181(79.7)$ & NA & $56(87.5)$ & $28(80.0)$ & NA & $265(64.6)$ \\
\hline Son & 0 & $3(3.7)$ & $1(1.6)$ & NA & NA & $4(1.0)$ \\
\hline Daughter & $5(2.2)$ & $10(12.3)$ & NA & 0 & NA & $15(3.7)$ \\
\hline Daughter-in-law & $5(2.2)$ & $16(19.8)$ & 0 & NA & NA & $21(5.1)$ \\
\hline
\end{tabular}

Values are presented as number (\%). 
Table 3. Role distribution by patient's gender

\begin{tabular}{|c|c|c|c|c|}
\hline & \multicolumn{2}{|c|}{ Gender } & \multirow{2}{*}{ Total } & \multirow{2}{*}{ p-value } \\
\hline & Male & Female & & \\
\hline \multicolumn{5}{|l|}{ Physical support ${ }^{\text {a) }}$} \\
\hline Self & $10(3.6)$ & $19(12.0)$ & $29(6.6)$ & $<0.001$ \\
\hline Spouse & $242(86.1)$ & $57(36.1)$ & $299(68.1)$ & \\
\hline Son & $12(4.3)$ & $25(15.8)$ & $37(8.4)$ & \\
\hline Daughter & $14(5.0)$ & 31 (19.6) & $45(10.3)$ & \\
\hline Daughter-in-law & $2(0.7)$ & $20(12.7)$ & $22(5.0)$ & \\
\hline \multicolumn{5}{|l|}{ Emotional support ${ }^{\text {b) }}$} \\
\hline Self & $11(3.9)$ & $11(7.0)$ & $22(5.0)$ & $<0.001$ \\
\hline Spouse & $236(84.0)$ & $52(32.9)$ & $288(65.6)$ & \\
\hline Son & $13(4.6)$ & $28(17.7)$ & $41(9.3)$ & \\
\hline Daughter & $16(5.7)$ & $45(28.5)$ & $61(13.9)$ & \\
\hline Daughter-in-law & $3(1.1)$ & $14(8.9)$ & $17(3.9)$ & \\
\hline \multicolumn{5}{|l|}{ Financial support ${ }^{\mathrm{c})}$} \\
\hline Self & $83(29.5)$ & $24(15.2)$ & $107(24.4)$ & 0.004 \\
\hline Spouse & $96(34.2)$ & $50(31.6)$ & $146(33.3)$ & \\
\hline Son & $73(26.0)$ & $64(40.5)$ & $137(31.2)$ & \\
\hline Daughter & $26(9.3)$ & $15(9.5)$ & $41(9.3)$ & \\
\hline Daughter-in-law & $3(1.1)$ & $2(1.3)$ & $5(1.1)$ & \\
\hline \multicolumn{5}{|l|}{ Decision support ${ }^{\mathrm{d})}$} \\
\hline Self & $67(23.8)$ & $26(16.5)$ & $93(21.2)$ & $<0.001$ \\
\hline Spouse & $134(47.7)$ & $41(25.9)$ & 175 (39.9) & \\
\hline Son & $56(19.9)$ & $55(34.8)$ & $111(25.3)$ & \\
\hline Daughter & $19(6.8)$ & $26(16.5)$ & 45 (10.3) & \\
\hline Daughter-in-law & $3(1.1)$ & $7(4.4)$ & $10(2.3)$ & \\
\hline \multicolumn{5}{|l|}{ Clinic visit supporte) } \\
\hline Self & $33(11.7)$ & $10(6.4)$ & $43(9.8)$ & $<0.001$ \\
\hline Spouse & $164(58.4)$ & $43(27.4)$ & $207(47.3)$ & \\
\hline Son & $39(13.9)$ & $34(21.7)$ & 73 (16.7) & \\
\hline Daughter & $28(10.0)$ & $35(22.3)$ & $63(14.4)$ & \\
\hline Daughter-in-law & $13(4.6)$ & $26(16.6)$ & $39(8.9)$ & \\
\hline \multicolumn{5}{|l|}{ Meal prep support ${ }^{\mathrm{f})}$} \\
\hline Self & $20(7.1)$ & $101(63.9)$ & $121(27.6)$ & $<0.001$ \\
\hline Spouse & $248(88.3)$ & $22(13.9)$ & $270(61.5)$ & \\
\hline Son & $2(0.7)$ & $4(2.5)$ & $6(1.4)$ & \\
\hline Daughter & $5(1.8)$ & $11(7.0)$ & $16(3.6)$ & \\
\hline Daughter-in-law & $5(1.8)$ & $20(12.7)$ & $25(5.7)$ & \\
\hline
\end{tabular}

Values are presented as number (\%). a-f) The exact numbers are as follows: $\left.\left.{ }^{\mathrm{a}} 7,{ }^{\mathrm{b}}\right) 10,{ }^{\mathrm{c})} 3,{ }^{\mathrm{d})} 5,{ }^{\mathrm{e}}\right) 14,{ }^{\mathrm{f})} 1$.

children got relatively more important. Between sons and daughters, sons provided more financial support than daughters $(30.7 \%$ vs. $9.5 \%)$, as well as decision-making support $(24.6 \%$ vs. $10.2 \%)$; daughters provided more emotional support than sons (13.9\% vs. $9.3 \%)$, as well as meal prep support (3.7\% vs. $1.0 \%)$.

When the analysis was limited to the patients who have only sons and daughters as available resources, this pattern of gender difference was consistent: sons stood out for financial (51.9\% vs. $17.3 \%)$ and decision-making support (49.4\% vs. $21.0 \%$ ) compared to daughters, while daughters' contribution to emotional support was slightly bigger (39.5\% vs. $35.8 \%$ ) compared to sons. Further comparison can be made between those with spouse and sons and those with spouse and daughters, in which the same pattern becomes more conspicuous: sons' contribution to finance $(34.4 \%$ vs. $8.6 \%)$ and 
Table 4. Role distribution by patient's age

\begin{tabular}{|c|c|c|c|c|c|c|}
\hline & \multicolumn{4}{|c|}{ Age group (yr) } & \multirow{2}{*}{ Total } & \multirow{2}{*}{ p-value } \\
\hline & $60-65$ & $66-70$ & $71-75$ & $\geq 76$ & & \\
\hline \multicolumn{7}{|l|}{ Physical supporta) } \\
\hline Self & $7(7.4)$ & $11(8.7)$ & $5(4.6)$ & $6(5.9)$ & $29(6.7)$ & 0.096 \\
\hline Spouse & $74(77.9)$ & $91(72.2)$ & $69(63.3)$ & $65(63.7)$ & $299(69.2)$ & \\
\hline Son & $3(3.2)$ & $7(5.6)$ & $15(13.8)$ & $12(11.8)$ & $37(8.6)$ & \\
\hline Daughter & $9(9.5)$ & $12(9.5)$ & $14(12.8)$ & $10(9.8)$ & $45(10.4)$ & \\
\hline Daughter-in-law & $2(2.1)$ & $5(4.0)$ & $6(5.5)$ & $9(8.8)$ & $22(5.1)$ & \\
\hline \multicolumn{7}{|c|}{ Emotional support $^{\mathrm{b}), \mathrm{c}}$} \\
\hline Self & $5(5.3)$ & $11(8.8)$ & $3(2.8)$ & $3(3.0)$ & $22(5.1)$ & 0.009 \\
\hline Spouse & $71(74.7)$ & $87(69.6)$ & $64(59.3)$ & $66(65.3)$ & $288(67.1)$ & \\
\hline Son & $3(3.2)$ & $8(6.4)$ & $19(17.6)$ & $11(10.9)$ & $41(9.6)$ & \\
\hline Daughter & $14(14.7)$ & $16(12.8)$ & $18(16.7)$ & $13(12.9)$ & $61(14.2)$ & \\
\hline Daughter-in-law & $2(2.1)$ & $3(2.4)$ & $4(3.7)$ & $8(7.9)$ & $17(4.0)$ & \\
\hline \multicolumn{7}{|l|}{ Financial support ${ }^{\mathrm{d})}$} \\
\hline Self & $31(33.0)$ & $36(27.9)$ & $17(15.6)$ & $23(22.1)$ & $107(24.5)$ & $<0.001$ \\
\hline Spouse & $45(47.9)$ & $51(39.5)$ & $31(28.4)$ & 19 (18.3) & $146(33.5)$ & \\
\hline Son & $12(12.8)$ & $26(20.2)$ & $51(46.8)$ & $48(46.2)$ & $137(31.4)$ & \\
\hline Daughter & $5(5.3)$ & $14(10.9)$ & $9(8.3)$ & $13(12.5)$ & $41(9.4)$ & \\
\hline Daughter-in-law & $1(1.1)$ & $2(1.6)$ & $1(0.9)$ & $1(1.0)$ & $5(1.1)$ & \\
\hline \multicolumn{7}{|l|}{ Decision support ${ }^{\mathrm{e}}$} \\
\hline Self & $31(33.3)$ & $31(24.2)$ & $16(14.7)$ & $15(14.4)$ & $93(21.4)$ & $<0.001$ \\
\hline Spouse & $42(45.2)$ & $59(46.1)$ & $40(36.7)$ & $34(32.7)$ & $175(40.3)$ & \\
\hline Son & $11(11.8)$ & $22(17.2)$ & $38(34.9)$ & $40(38.5)$ & $111(25.6)$ & \\
\hline Daughter & $9(9.7)$ & $13(10.2)$ & $13(11.9)$ & $10(9.6)$ & $45(10.4)$ & \\
\hline Daughter-in-law & 0 & $3(2.3)$ & $2(1.8)$ & $5(4.8)$ & $10(2.3)$ & \\
\hline \multicolumn{7}{|l|}{ Clinic visit support $\left.{ }^{\mathrm{f}}\right)$} \\
\hline Self & $14(14.9)$ & $14(11.2)$ & $8(7.5)$ & $7(7.0)$ & $43(10.1)$ & 0.201 \\
\hline Spouse & $50(53.2)$ & $68(54.4)$ & $47(44.3)$ & $42(42.0)$ & $207(48.7)$ & \\
\hline Son & $13(13.8)$ & $17(13.6)$ & $22(20.8)$ & $21(21.0)$ & $73(17.2)$ & \\
\hline Daughter & $12(12.8)$ & $18(14.4)$ & $17(16.0)$ & $16(16.0)$ & $63(14.8)$ & \\
\hline Daughter-in-law & $5(5.3)$ & $8(6.4)$ & $12(11.3)$ & $14(14.0)$ & $39(9.2)$ & \\
\hline \multicolumn{7}{|l|}{ Meal prep supports) } \\
\hline Self & $30(31.6)$ & $35(26.9)$ & $31(28.4)$ & $25(24.0)$ & $121(27.6)$ & 0.042 \\
\hline Spouse & $62(65.3)$ & $85(65.4)$ & $65(59.6)$ & $58(55.8)$ & $270(61.6)$ & \\
\hline Son & 1 (1.1) & $2(1.5)$ & $2(1.8)$ & $1(1.0)$ & $6(1.4)$ & \\
\hline Daughter & $1(1.1)$ & $3(2.3)$ & $3(2.8)$ & $9(8.7)$ & $16(3.7)$ & \\
\hline Daughter-in-law & $1(1.1)$ & $5(3.8)$ & $8(7.3)$ & $11(10.6)$ & $25(5.7)$ & \\
\hline
\end{tabular}

Values are presented as number (\%). ${ }^{\mathrm{a}-\mathrm{g}} \mathrm{T}$ The exact numbers are: $\left.\left.\left.\left.{ }^{\mathrm{a}} 7,{ }^{\mathrm{b}}\right) 10,{ }^{\mathrm{c}} 5, \mathrm{~d}\right) 3, \mathrm{e}\right) 5,{ }^{\mathrm{f}} 14,{ }^{\mathrm{g}}\right) 1$ cell $(25.0 \%)$ have expected count less than 5 , and thus the interpretation of the $\chi^{2}$ statistics warrants caution.

decision-making ( $21.9 \%$ vs. $17.1 \%)$ is even higher than daughters'; and daughters' contribution to emotional support $(22.9 \%$ vs. $1.6 \%)$ than sons'.

\section{2) By patient's gender}

To compare the responsibility distribution depending on the patient's gender, chi-square statistics was used after deleting the options with less than five cases. This left self, spouse, sons, daughters, and daughters-in-law in the analyses. As Table 3 shows, more male patients tend to rely on spousal support on physical ( $86.1 \%$ vs. $36.1 \%)$ and emotional needs $(84.0 \%$ vs. $32.9 \%)$ than female patients. More female patients seemed to depend on their daughters for physical support (19.6\% vs. $5.0 \%)$ than male patients, as well as for emotional support (28.5\% vs. $5.7 \%$ ). As far as financial needs 
are concerned, more male patients reported the couple cared for themselves than female patients' report (63.7\% vs. 46.8\%). Still, more female patients reported their reliance on sons than male patients did in terms of financial needs ( $40.5 \%$ vs. $26.0 \%$ ) and decision-making ( $34.8 \%$ vs. $19.9 \%$ ). On mealprep, male patients relied heavily on their spouses $(88.3 \%)$, whereas female patients cared for themselves $(63.9 \%)$ if not relying on their daughters-in-law $(12.7 \%)$.

In order to see whether this gender difference could be attributed to the availability of spouse resource, additional analyses were conducted with only the patients who have spouses (S1 Table). In this case, the difference between male and female patients' reliance on spousal support was less noteworthy, regarding physical $(94.1 \%$ vs. $75 \%)$, emotional $(91.8 \%$ vs. $68.4 \%)$, financial $(37.5 \%$ vs. $64.5 \%)$, and decisionmaking ( $52.3 \%$ vs. $53.9 \%)$ support. Still, the adult children's gender difference showed consistent pattern, where sons took up the responsibility of financial and decision-making needs while daughters took up the share of physical and emotional support, when the patient's spouse was not available.

\section{3) By patient's age}

To compare the responsibility distribution depending on the patient's age, chi-square statistics was used after deleting the options with less than five cases. This left self, spouse, sons, daughters, and daughters-in-law in the analyses. Table 4 shows the results for those who are 60 through 65 years old, 66 through 70 years old, 71 through 75 years old, and 76 years old or above. The older the patients were, the more likely they relied on their adult children's support. Even though spouse was the most important source of emotional support for all age groups, the percentage declines rather gradually $(74.7 \%, 69.6 \%, 59.3 \%$, and $65.3 \%)$, which is replaced by their increasing reliance on daughters and daughters-in-law $(16.8 \%, 15.2 \%, 20.4 \%$, and $20.8 \%)$ and on sons $(3.2 \%, 6.4 \%, 17.6 \%$, and $10.9 \%)$. This pattern is more conspicuous in financial and decision-making support. Patients reported taking care of themselves less and less, financially $(80.9 \%, 66.5 \%, 44.4 \%$, and $40.4 \%)$ and in decision-making $(78.5 \%, 70.3 \%, 51.4 \%$, and $47.1 \%)$. The decline seems to be taken over by their sons in finance $(12.8 \%, 20.2 \%, 46.8 \%$, and $46.2 \%)$ and in decision-making $(11.8 \%, 17.2 \%, 34.9 \%$, and $38.5 \%)$.

In order to see whether this age difference could be attributed to the availability of spouse resource, additional analyses were conducted with only the patients who have spouses (S2 Table). Above all, the patient's dependence on spouse was rather steady across domains of support: most obviously for emotional support $(88.8 \%, 85.3 \%, 83.1 \%$, and $89.0 \%)$, clinic visit support $(62.5 \%, 65.7 \%, 59.7 \%$, and $56.2 \%)$, and meal prep support $(77.5 \%, 83.3 \%, 84.4 \%$, and $79.5 \%)$. Still, the same pattern of sons' taking over the role was observed on the financial $(11.3 \%, 14.7 \%, 40.3 \%$, and $41.1 \%)$ and decisionmaking needs $(10.0 \%, 12.7 \%, 26.0 \%$, and $28.8 \%)$.

\section{Discussion}

\section{Summary of the results and implications}

As one of the first attempts to describe different sources of support in terms of cancer caregiving, the current study provided insight on the responsibility distribution among family members in Korean cultural context. Particularly by employing in-person administration of the survey, the responses from elderly cancer patients were recorded accurately by trained research assistants. Also the current study is composed of a nationwide sample from diverse geographical areas, and thus the findings can suggest multiple clinical implications generalizable to the population.

The results show, first of all, caregiving tasks are shared by multiple caregivers. Remarkably few studies have taken into account the involvement of multiple caregivers and how best to tailor existing interventions and assess outcomes for such circumstances, even while in taking care of a cancer patient, the responsibility gets easily imposed on one primary caregiver and the caregiver's experience is reported to be negative and perceived as a burden [16]. Understanding the characteristics and resources of the family can therefore help service providers work effectively with multiple caregiver families or groups and suggest strategies for sharing caregiving responsibilities.

More specifically, the current study showed the patients' heavy reliance on their spouses, if available, particularly on physical, emotional, clinic visit, and meal prep needs. Considering that all the participants of the current study were 60 years old or above, couples take care of each other even if the caregiver might not be in a good shape either. Speaking of caregivers of the general U.S. population, for example, 34 percent of the caregivers are 65 years old or above [17]. Together with this statistics, the need of strategic interventions to support the elder patient and caregiver dyads is heightened.

In the current study, different gender roles were evidenced as well. Adult children, sons and daughters, took up different tasks: sons provided more financial support and decision-making support than daughters, while daughters provided more emotional support than sons. In addition, male patients showed more reliance on their spouses than female patients did, and the difference seemed to be taken 
over by daughters and daughters-in-law for female patients, particularly on physical and emotional needs. Again, when the financial and decision-making support are involved, however, patients' reliance on female caregivers decreases. Male spouses and sons, instead of female spouses and daughters, took up the responsibility of providing support on those needs. In a Confucian culture, like Korea, men are viewed as a source of monetary support and a decision maker in family [18]. On the other hand, women are expected to take care of the house-chores and to provide emotional and daily-living related support to the family. The results were consistent with this gender expectation, including the contribution of daughters-in-law on meal prep support.

When patients' age was counted, the older the patients were, the more they depended on their adult children. It is not surprising to see adult children take over the responsibility as patients age and get weaker. Particularly in the era with nuclear families as a norm, the aging population and the caregiving of the elderly concerns many families. The coordination of different types of support is necessary, according to the current study and the literature [12-16]. And thus it is recommended to involve the multiple family members, including sons, daughters, and daughters-in-law, in planning any support programs for the elderly cancer patients in diverse situations with respect to different family structure, gender, and age.

In sum, the literature reports that the family caregivers of cancer patients encounter multiple stressors as well [1-3, 12-16]. However, we do not recognize their needs or their struggles yet in the cancer care system. Considering that the family caregivers are not necessarily educated in healthrelated fields, certain information on cancer and its care will help. In providing professional care, the medical professionals need to acknowledge different dynamics in family, if hard, so that the interventions could be more effective and efficient.

\section{Limitations and suggestions}

In the current study, the type of cancer was limited to the three prevalent ones in Korea: gastric, colorectal, and lung cancers. More diverse sample of cancer types is desirable as the patients' reliance on family caregivers might vary depending on the types of cancer. For example, caregivers pay close attention to the meal prep for gastric and colorectal cancer patients as they believe in the consequences of food intake [12]. On the contrary, lung cancer patients tend to blame themselves for having smoked for a long time [19] and experience internalized stigma, and thus might rely more on their caregivers for emotional support. Such cancers that involve gender-specific expectations as breast cancer and prostate cancer might as well connotate different pattern of support seeking between patients and caregivers.

A longitudinal design that includes multiple types of cancer, therefore, can provide in-depth insights for the needs and the adaptation of cancer patients and their family caregivers over the course of their cancer care and survivorship. The majority of the current study participants $(96.6 \%)$ have had cancer for less than 2 years, which made it hard to notice a change according to the time since diagnosis. However, it is possible to have a shift from physical and decision-making needs in going through aggressive treatments in the first few years since diagnosis to emotional needs in returning to their routine. Therefore, in a longitudinal design, the interaction between patient's family structure, gender, age, and the caregivers' support domains can be more specific and provide in-depth insights when the patients serve as their own control group with repeated measurements.

Notwithstanding its limitations, the current study provides insights on the types of support and the providers for elderly cancer care among family members. Above all, cancer caregiving for the elderly takes multiple family caregivers, including the phenomenon of elderly cancer patients' heavy reliance on their spouses, even while the spouses could be very old as well, being later complemented by their adult children who take up different responsibilities to provide care for their parents. Further, the patients' reliance on multiple sources of support differed depending on their family type, gender, and age. In the cultural context where individual family takes the caregiving role, therefore, the current study testifies the importance of understanding the diverse family environments and suggests the need to develop interventions involving multiple caregivers.

\section{Electronic Supplementary Material}

Supplementary materials are available at Cancer Research and Treatment website (https:// www.e-crt.org).

\section{Conflicts of Interest}

Conflict of interest relevant to this article was not reported.

\section{Acknowledgments}

This study was sponsored by the National Cancer Center (Grant No. 1610312) and partially by the National Research Foundation (Grant No. 2017R1C1B5076469). 


\section{References}

1. Glajchen M. The emerging role and needs of family caregivers in cancer care. J Support Oncol. 2004;2:145-55.

2. Gaston-Johansson F, Lachica EM, Fall-Dickson JM, Kennedy MJ. Psychological distress, fatigue, burden of care, and quality of life in primary caregivers of patients with breast cancer undergoing autologous bone marrow transplantation. Oncol Nurs Forum. 2004;31:1161-9.

3. Haley WE. Family caregivers of elderly patients with cancer: understanding and minimizing the burden of care. J Support Oncol. 2003;1(4 Suppl 2):25-9.

4. Dilworth-Anderson P, Goodwin PY, Williams SW. Can culture help explain the physical health effects of caregiving over time among African American caregivers? J Gerontol B Psychol Sci Soc Sci. 2004;59:S138-45.

5. Jones PS, Zhang XE, Jaceldo-Siegl K, Meleis AI. Caregiving between two cultures: an integrative experience. J Transcult Nurs. 2002;13:202-9.

6. Wallhagen MI, Yamamoto-Mitani N. The meaning of family caregiving in Japan and the United States: a qualitative comparative study. J Transcult Nurs. 2006;17:65-73.

7. Pinquart M, Sorensen S. Ethnic differences in stressors, resources, and psychological outcomes of family caregiving: a meta-analysis. Gerontologist. 2005;45:90-106.

8. Knight BG, Sayegh P. Cultural values and caregiving: the updated sociocultural stress and coping model. J Gerontol B Psychol Sci Soc Sci. 2010;65:5-13.

9. Scharlach AE, Kellam R, Ong N, Baskin A, Goldstein C, Fox PJ. Cultural attitudes and caregiver service use: lessons from focus groups with racially and ethnically diverse family caregivers. J Gerontol Soc Work. 2006;47:133-56.

10. National Cancer Information Center [Internet]. Goyang: National Cancer Center; 2017 [cited 2017 Jul 12]. Available from: http: // www.cancer.go.kr/mbs/cancer/subview.jsp?id =cancer_040401000000.
11. Goo AJ, Shin DW, Yang HK, Park JH, Kim SY, Shin JY, et al. Cross-cultural application of the Korean version of the EORTC QLQ-ELD14 questionnaire for elderly patients with cancer. J Geriatr Oncol. 2017;8:271-6.

12. Jeong A, An JY, Park JH, Park K. What cancer means to the patients and their primary caregivers in the family-accounted Korean context: a dyadic interpretation. Psychooncology. 2017;26:1777-83.

13. Wolff JL, Roter DL, Given B, Gitlin LN. Optimizing patient and family involvement in geriatric home care. J Healthc Qual. 2009;31:24-33.

14. Shin DW, Cho J, Roter DL, Kim SY, Sohn SK, Yoon MS, et al. Preferences for and experiences of family involvement in cancer treatment decision-making: patient-caregiver dyads study. Psychooncology. 2013;22:2624-31.

15. Shin DW, Cho J, Roter DL, Kim SY, Park JH, Yang HK, et al. Patient's cognitive function and attitudes towards family involvement in cancer treatment decision making: a patientfamily caregiver dyadic analysis. Cancer Res Treat. 2018;50: 681-90.

16. Park CH, Shin DW, Choi JY, Kang J, Baek YJ, Mo HN, et al. Determinants of the burden and positivity of family caregivers of terminally ill cancer patients in Korea. Psychooncology. 2012;21:282-90.

17. Family Caregiver Alliance [Internet]. San Franciso, CA: Family Caregiver Alliance; 2017 [cited 2017 Nov 21]. Available from: https:// www.caregiver.org/ caregiver-statistics-demographics.

18. Park BJ. Patriarchy in Korean society: substance and appearance of power. Korea J. 2001;41:48-73.

19. Chapple A, Ziebland S, McPherson A. Stigma, shame, and blame experienced by patients with lung cancer: qualitative study. BMJ. 2004;328:1470. 